Acta Crystallographica Section D

Biological Crystallography

ISSN 0907-4449

\title{
The cofactor-induced pre-active conformation in PhoB
}

PhoB is an Escherichia coli transcription factor from a twocomponent signal transduction system that is sensitive to limiting environmental phosphate conditions. It consists of an $\mathrm{N}$-terminal receiver domain (RD) and a C-terminal DNAbinding domain. The protein is activated upon phosphorylation at the $\mathrm{RD}$, an event that depends on $\mathrm{Mg}^{2+}$ binding. The structure of $\mathrm{PhoB} \mathrm{RD}$ in complex with $\mathrm{Mg}^{2+}$ is presented, which shows three protomers in the asymmetric unit that interact across two different surfaces. One association is symmetric and has been described as a non-active dimerization contact; the other involves the $\alpha 4-\beta 5-\alpha 5$ interface and recalls the contact found in activated PhoB. However, here this last interaction is not perfectly symmetric and helix $\alpha 4$, which in the activated molecule undergoes a helical shift, becomes strongly destabilized in one of the interacting monomers. All protomers bind the cation in a similar manner but, interestingly, at the prospective binding site for the phosphate moiety the side chains of either Glu88 (in helix $\alpha 4$ ) or Trp54 alternate and interact with active-site atoms. When Glu88 is inside the cavity, helix $\alpha 4$ is arranged similarly to the unliganded wild-type structure. However, if Trp54 is present, the helix loses its contacts with the active-site cavity and vanishes. Accordingly, the presence of Trp54 in the active site induces a flexible state in helix $\alpha 4$, potentially allowing a helical shift that phosphorylation would eventually stabilize.

\section{Introduction}

A large number of bacterial pathways depend on twocomponent signal transduction systems (2C-STS) to transmit extracellular or intracellular signals that activate cell metabolism. 2C-STSs govern chemotaxis, quorum sensing, nutrient uptake, nitrogen fixation, production of antibiotics, osmoregulation, sporulation, hormone-dependent developmental processes and pathogen invasion (Hoch, 2000; Stock et al., 2000; Wang et al., 2002; Wolanin et al., 2002). 2C-STS are widespread in archaea, eubacteria, eukaryotic cell organelles and in yeast and plants, where these pathways are part of more complex signal transduction networks (Pao \& Saier, 1997; Stock et al., 2000; Forsberg et al., 2001; Santos \& Shiozaki, 2001; Grefen \& Harter, 2004). Eubacteria containing 2C-STSs include pathogens, which are particularly able to adapt to changing environments. As such systems are absent in mammals, they can be envisaged as targets for the development of new antimicrobial drugs that will increase the medical armamentarium available in times of increasing bacterial antibiotic resistance (Barrett \& Hoch, 1998; Stephenson \&

Hoch, 2002).
Received 29 March 2006

Accepted 26 June 2006

PDB Reference: PhoB, 2yin, r2yinsf.
(C) 2006 International Union of Crystallography Printed in Denmark - all rights reserved 
A typical 2C-STS system consists of a sensor component and a response regulator ( $\mathrm{RR})$ and may include additional regulatory components (Wick \& Egli, 2004). The sensor is usually a membrane-spanning receptor consisting of an external ligand-binding domain, the sensor module and a cytosolic transmitter domain with histidine kinase activity. Indirect or direct binding of a ligand to the sensor triggers the transmission of the signal across the receptor molecule and hence across the membrane, resulting in phosphorylation of a specific conserved histidine in the cytosolic domain. The cognate RR subsequently directly or indirectly promotes a phosphotransfer from the sensor to a strictly conserved aspartate of its own receiver domain (RD). In most cases, the $\mathrm{RR}$ has additional domains, including a C-terminal effector domain (ED) whose activity is modulated by phosphorylation of the N-terminal RD. Phosphorylated RRs have a variety of responses, depending on the 2C-STS pathway. For example, the ED may bind to a cognate DNA sequence or the protein may change its oligomeric state and/or activate an enzymatic function. Dephosphorylation of the RR, either by a specific phosphatase or by the RR itself, switches off the system. Both phosphorylation and dephosphorylation are magnesiumdependent reactions (Lukat et al., 1990; McCleary \& Stock, 1994; Aizawa et al., 2000; Stock et al., 2000; Falke \& Hazelbauer, 2001).

In Escherichia coli, the 229-amino-acid transcription factor PhoB RR comprises an N-terminal RD (residues 1-124) and a C-terminal ED with DNA-binding properties (residues 131229) separated by a flexible six-residue linker. Together with its cognate sensor histidine kinase PhoR (Makino et al., 1989), it is part of a 2C-STS that is sensitive to extracellular inorganic phosphate $\left(\mathrm{P}_{\mathrm{i}}\right)$ levels (Wanner, 1996). In particular, PhoR detects changes in environmental $\mathrm{P}_{\mathrm{i}}$ concentration either directly through its extracellular domain or through the highaffinity phosphate transporter (encoded by the PstSCAB genes), along with the ancillary protein PhoU. PhoR remains unphosphorylated while the organism grows in the presence of excess $\mathrm{P}_{\mathrm{i}}$. As soon as extracellular phosphate falls to starvation levels, PhoR autophosphorylates a conserved histidine residue from its histidine phosphorylation domain. The phosphate is subsequently transferred in a magnesium-dependent manner to a conserved aspartate residue (Asp53) within the N-terminal RD of PhoB. Upon phosphorylation, the PhoB ED binds with higher affinity to specific pho-box DNA sequences in the promoters of the $\mathrm{PHO}$ regulon, which comprises several genes and operons (McCleary, 1996). PhoB belongs to the OmpR/ PhoB subfamily of RR, which are $\sigma^{70}$ RNA polymerase subunit-dependent transcription factors. Transcription activation of the $\mathrm{PHO}$ regulon allows $E$. coli to bind environmental $\mathrm{P}_{\mathrm{i}}$ with higher affinity and assimilate phosphorus from alternative sources such as pyrophosphate or metaphosphate (Wanner, 1993). To date, the three-dimensional structure of full-length PhoB has not been determined and therefore the structural details of the interaction between the domains are not known. Biochemical data demonstrate that the N-terminal RD inhibits the C-terminal ED DNA-binding activity. The removal of the RD results in a protein that binds DNA more tightly and activates transcription (Ellison \& McCleary, 2000). Moreover, cross-linking studies on the full-length protein provided evidence that non-phosphorylated $\mathrm{PhoB}$ is able to form dimers and it was proposed that in the non-activated state there is a rapid equilibrium between the monomeric and dimeric forms that is shifted towards dimers by phosphorylation (McCleary, 1996). In contrast, functional studies of PhoB RD fused to the DNA-binding domain of the lambda repressor demonstrated that the RD only forms active dimers upon phosphorylation, suggesting that the PhoB ED prevents formation of the active dimer (Fiedler \& Weiss, 1995). All this information led to two apparently contradictory scenarios: on one hand dimerization already happens before activation (McCleary, 1996), while on the other the inactive protein is a monomer owing to ED inhibition of the RD and only upon phosphorylation is the inhibition released and the protein becomes a dimer through the RD (Fiedler \& Weiss, 1995). In this process, phosphorelay is meant to trigger interdomain rearrangements that release the inhibition and allow a dimermediated response.

We have previously determined the three-dimensional structures of the metal-free N-terminal domain of PhoB (referred to in the following as apo- $\mathrm{PhoB}^{\mathrm{R}}$ ), as well as that of the C-terminal domain either unbound or in complex with DNA. Apo-PhoB ${ }^{R}$ reveals strong structural similarity to RDs of the response regulator superfamily, but with a symmetric homodimeric quaternary arrangement not found in any orthologue (Solà et al., 1998, 1999). The PhoB ED structure consists of a modified winged helix-turn-helix motif where DNA recognition occurs in tandem with an $\alpha$-helix bound to the major groove and a wing interacting with the minor groove (Blanco et al., 2002). The twofold apo- $\mathrm{PhoB}^{\mathrm{R}}$ dimer positions the C-terminal ends of each RD at opposite sides, so that the two subsequent ED cannot simultaneously interact in tandem with a DNA molecule. In consequence, the apo-PhoB ${ }^{\mathrm{R}}$ arrangement may correspond to the inactivated state of PhoB. In the present work, we report the structure of PhoB RD in complex with $\mathrm{Mg}^{2+}\left(\mathrm{PhoB}^{\mathrm{RM}}\right)$. This structure shows two different interfaces between the three protomers in the asymmetric unit, each involving a unique interaction surface. One is similar to the dimer interface in the apo-PhoB ${ }^{\mathrm{R}}$ structure and the other is a small quasi-symmetric proteinprotein interaction. The latter involves highly conserved residues and recalls a larger and symmetric interface found in the structure of PhoB RD activated (referred to in the following as $\mathrm{PhoB}^{\mathrm{RAc}}$ ) with the phosphoryl analogue beryllium fluoride $\left(\mathrm{BeF}_{3}^{-}\right.$; Bachhawat et al., 2005). Interestingly, this second arrangement putatively places the two EDs close to each other at one edge of the dimer. Moreover, the inclusion of the cation in the active site results in the formation of a similar hydrogen-bonding network in all $\mathrm{PhoB}^{\mathrm{RM}}$ protomers. However, the three active sites show heterogeneity at the specific area that in $\mathrm{PhoB}^{\mathrm{RAc}}$ is occupied by $\mathrm{BeF}_{3}^{-}$as, depending on the molecule in the crystal, it is alternatively filled by Trp54 or Glu88 side chains. In both cases the side chains interact with the active-site network, but the presence of Trp54 in the cavity correlates with a highly flexible 
Table 1

Data-collection and refinement statistics for WT PhoB RD- $\mathrm{Mg}^{2+}$ complex.

Values in parentheses are for the last shell.

\begin{tabular}{ll}
\hline Wavelength $(\AA)$ & 0.837 \\
Space group & $C 222_{1}$ \\
Unit-cell parameters $(\AA)$ & $a=50.7, b=105.8, c=135.5$ \\
Estimated mosaicity $\left({ }^{\circ}\right)$ & 0.75 \\
No. of measurements & 110494 \\
No. of unique reflections & 20372 \\
Average multiplicity & $5.4(4.8)$ \\
Resolution range $(\AA)$ & $45.2-2.08(2.19-2.08)$ \\
$\left.R_{\text {merge }} \dagger \%\right)$ & $7.6(38.8)$ \\
Completeness $(\%)$ & $91.4(78.9)$ \\
$\langle I\rangle / \sigma(\langle I\rangle)$ & $5.2(1.9)$ \\
Resolution range used for refinement $(\AA)$ & $45.2-2.08$ \\
No. of reflections $($ working set/test set) & $19679 / 658$ \\
$R$ factorł $(\%)$ & 23.1 \\
Free $R$ factor§ $(\%)$ & 30.5 \\
R.m.s.d. bonds $(\AA)$ & 0.016 \\
R.m.s.d. angles $\left({ }^{\circ}\right)$ & 1.50 \\
R.m.s.d. bonded $B$ factors $\left(\AA^{2}\right)$ & 1.58 \\
No. of non- $\mathrm{H}$ protein atoms & 2746 \\
Water molecules & 108 \\
Metal ions & $3\left(\mathrm{Mg}^{2+}\right)$ \\
Average $B$ factors $\left(\AA^{2}\right)$ & \\
Protein atoms & 17.2 \\
Solvent molecules & 20.4 \\
$\quad$ Metal ions & 17.1 \\
\hline
\end{tabular}

$\dagger R_{\text {merge }}=\left[\sum_{h k l} \sum_{i}\left|I_{i}(h k l)-\langle I(h k l)\rangle\right| / \sum_{h k l} \sum_{i} I_{i}(h k l)\right] \times 100$, where $I_{i}(h k l)$ is the $i$ th intensity measurement of reflection $h k l$ and $\langle I(h k l)\rangle$ is its average intensity. $\$ R$ factor $=\left(\sum_{h k l}|| F_{\text {obs }}|-k| F_{\text {calc }}|| / \sum_{h k l}\left|F_{\text {obs }}\right|\right) \times 100$. \& The free $R$ factor is the $R$ factor for a test set of reflections $(>500)$ not used during the refinement.

conformation of helix $\alpha 4$, a segment at the surface involved in the quasi-symmetric interaction. Our results suggest that upon $\mathrm{Mg}^{2+}$ binding, this surface increases its flexibility, allowing the structural rearrangement of helix $\alpha 4$ needed for the active oligomerization.

\section{Materials and methods}

\subsection{Protein expression and purification}

Native apo-PhoB RD was prepared and purified essentially as described elsewhere (Solà et al., 1998, 1999). Briefly, a DNA fragment comprising the nucleic acid sequence encoding residues Met1-Ala127 of PhoB RD was subcloned into the pBAT-4 expression vector (Peränen et al., 1996) and overexpressed in E. coli strain BL21 (DE3) at $298 \mathrm{~K}$. The lysis buffer contained $20 \mathrm{mM}$ Tris- $\mathrm{HCl} \mathrm{pH} \mathrm{8,} \mathrm{which} \mathrm{was} \mathrm{used} \mathrm{in}$ subsequent steps of protein purification. The soluble fraction was purified in two consecutive steps of FPLC size-exclusion chromatography on a HiLoad 26/60 Superdex 75 column (Amersham Pharmacia). The sample was finally concentrated to $6 \mathrm{mg} \mathrm{ml}^{-1}$ and stored at $193 \mathrm{~K}$.

\subsection{Complex formation, protein crystallization, data collection and processing}

$\mathrm{Mg}^{2+}$-bound PhoB RD crystals were obtained by the hanging-drop vapour-diffusion method in Linbro crystallization plates from drops comprising $3 \mu \mathrm{l}$ protein solution in the same buffer as used during studies with the unbound protein (Solà et al., 1998) and $6 \mu \mathrm{l}$ reservoir solution containing $20 \%(w / v)$ polyethylene glycol (PEG) 4000 (Fluka), $0.1 M$ Tris- $\mathrm{HCl}$ (Fluka) pH 8.0, 0.4 M magnesium acetate (J. T. Baker) and $0.02 \%$ sodium azide (J. T. Baker). These crystals belong to a new crystal form, space group $C 222_{1}$, with unit-cell parameters $a=50.7, b=105.8, c=135.5 \AA$ and three molecules per asymmetric unit $\left(V_{\mathrm{M}}=2.1 \AA^{3} \mathrm{Da}^{-1} ; 41 \%\right.$ solvent content; Matthews, 1968). For comparison, apo-PhoB RD crystals belong to space group $P 2_{1} 2_{1} 2_{1}$, with unit-cell parameters $a=34.1, b=60.4, c=120.0 \AA$ and a dimer (WT-A and WT-B) in the asymmetric unit. In order to preserve crystals for transport and during data collection, they were flash-cryocooled in liquid nitrogen after soaking them in a solution containing 35\% PEG 4000 for about 20 min. X-ray diffraction data were collected at $100 \mathrm{~K}$ on $\mathrm{CCD}$ area detectors at the ESRF synchrotron (Grenoble, France) beamlines ID14-EH2 and BM-16 and at beamline BW7B at DESY (Hamburg, Germany). Data were indexed and integrated with MOSFLM (Leslie, 1991) and scaled, merged and reduced with SCALA (Evans, 1993a). Data-collection and processing statistics are given in Table 1.

\subsection{Structure solution and refinement}

The structure of $\mathrm{Mg}^{2+}$-bound $\mathrm{PhoB} \mathrm{RD}$ was solved by Patterson search (Huber, 1965) with the AMoRe package (Navaza, 1994) using the apo-PhoB RD X-ray structure as a search model (PDB code 1b00; Solà et al., 1999). Rotation and translation functions were calculated using data in the 15$4.0 \AA$ resolution range. Firstly, a dimer as found in the apo structure was employed as a model and when its rotation and position had been elicited a second search using a monomer was undertaken to find the third molecule present in the crystallographic asymmetric unit. These calculations rendered two clear solutions, which showed a cumulative correlation coefficient in structure-factor amplitudes (defined in Navaza, 1994 ) of $55.2 \%$ (second highest unrelated $43.0 \%$ ) and a crystallographic $R$ factor of $43.5 \%$ (second highest unrelated $48.0 \%$ ). The appropriately rotated and translated coordinates were refined using the maximum-likelihood criteria with $C N S$ v.1.0 (Brünger et al., 1998) and REFMAC5 (Murshudov et al., 1997) employing bulk-solvent and anisotropic temperaturefactor correction and using all data except for a sufficient number of reflections used for the cross-validation free $R$ factor, which was monitored throughout during refinement. Refinement further included NCS restraints in the initial stages and TLS refinement as implemented in REFMAC5. The correctness of the solutions was confirmed by inspection of $\sigma_{\mathrm{A}}$-weighted $\left|2 m F_{\text {obs }}-d F_{\text {calc }}\right|$ and $\left|m F_{\text {obs }}-d F_{\text {calc }}\right|$ Fourier maps, which showed clear density for deviating regions of the polypeptide chain and side chains, in particular around the metal-binding sites. After initial simulated-annealing refinement, cycles of positional refinement and temperature-factor refinement were alternated with manual model building using TURBO-FRODO (Carranza et al., 1999) on a Silicon Graphics workstation. In the final steps of the refinement process, solvent molecules were placed manually at appropriate posi- 


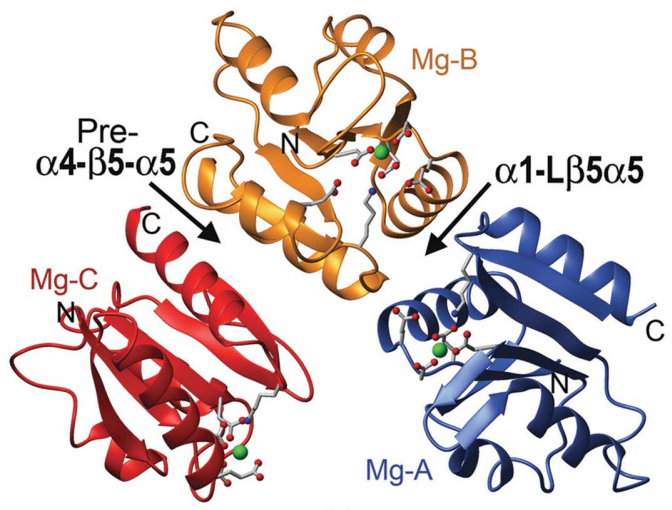

(a)

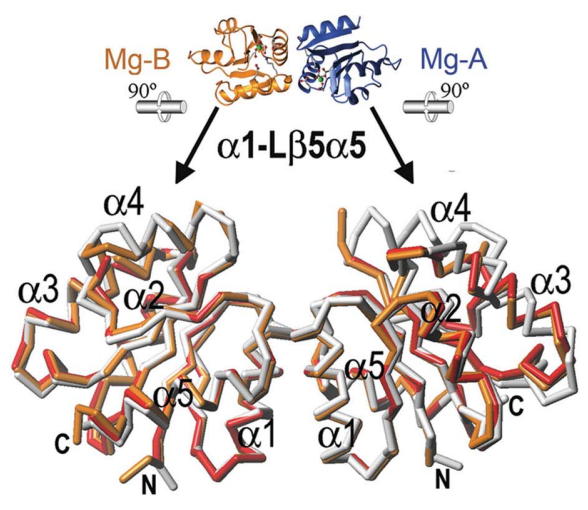

(c)

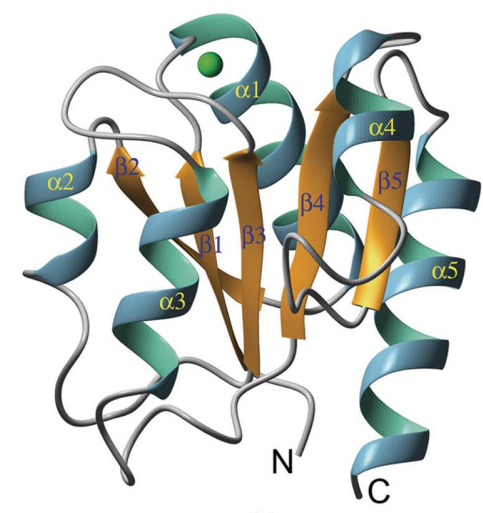

(b)

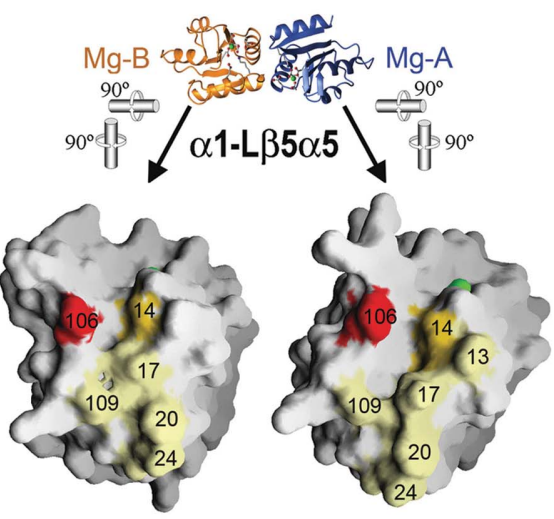

$(d)$

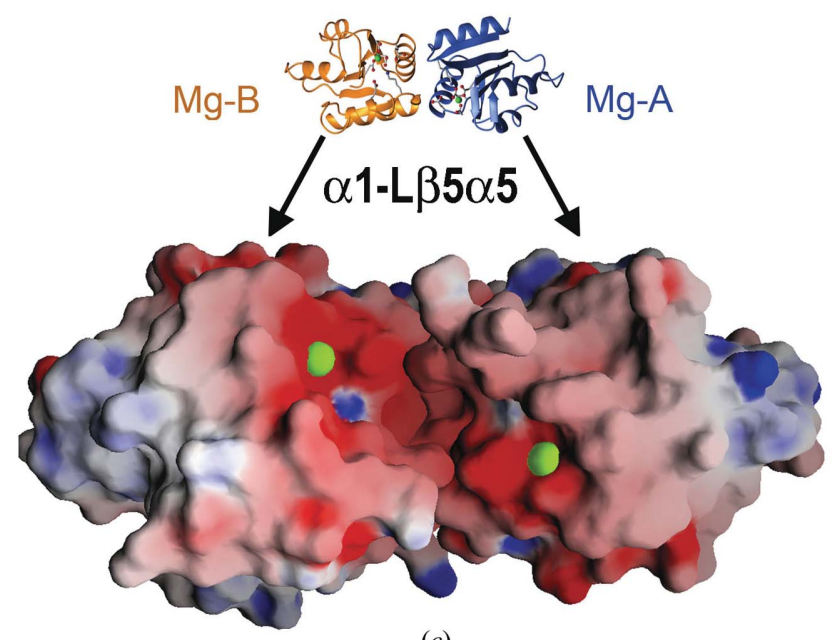

(e)

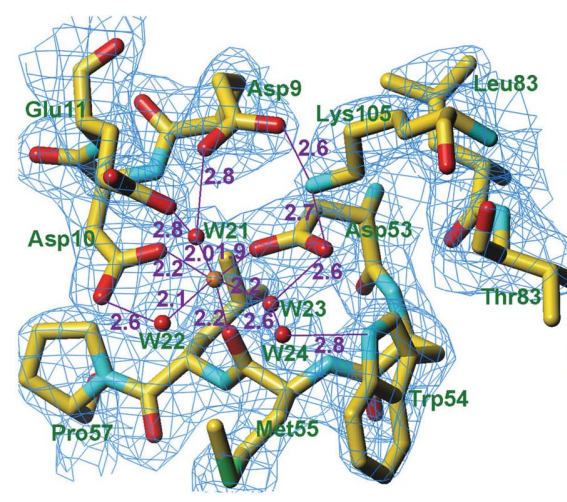

$(f)$ tions if a clear positive difference density was present at $2.5 \sigma$ above average. The magnesium ions were identified on the basis of coordination geometry and ligand distances. The final $\mathrm{Mg}^{2+}$-bound RD structure contains residues $3 \mathrm{~A}-121 \mathrm{~A}$ (excepting residues $87 \mathrm{~A}-95 \mathrm{~A}$ of helix $\alpha 4$ ), 1B-124B, 3C-122C (excepting residues $85 \mathrm{C}-96 \mathrm{C}$ of helix $\alpha 4$ ), three magnesium cations and 108 solvent molecules (see Table 1). Accordingly, a total of 39 amino acids $(10 \%)$ are flexible and not defined by the electron density. This results in a high free $R$ factor. A Ramachandran plot generated with PROCHECK (Laskowski et al., 1993) shows all the residues in most favoured or in additional allowed regions except for

\section{Figure 1}

PhoB RD in complex with $\mathrm{Mg}^{2+}$. (a) Richardson diagram of the three molecules present in the crystal asymmetric unit: $\mathrm{Mg}-\mathrm{A}$ (blue), Mg-B (orange) and $\mathrm{Mg}-\mathrm{C}$ (red). The magnesium ions are represented as green spheres and the coordinating protein residue side chains are shown as ball-and-stick models. (b) Richardson diagram of the PhoB RD molecule Mg-B. Helices are shown as blue ribbons and labelled $(\alpha 1-\alpha 5)$ and $\beta$-strands as orange arrows $(\beta 1-\beta 5)$. The positions of the $\mathrm{N}$ - and the C-termini are also depicted. The green sphere signifies the bound magnesium ion. (c) Superimposition of the $\mathrm{C}^{\alpha}$ traces of the dimers linked through an $\alpha 1$ $\mathrm{L} \beta 5 \alpha 5$ interface as found in WT-A/B (white), $\mathrm{Mg}-\mathrm{A} / \mathrm{B}$ (orange) and $\mathrm{Mg}-\mathrm{C} / \mathrm{C}^{\prime}$ (red). Note that helix $\alpha 3$ undergoes a rigid-body displacement on going from the apo protomer (on the right) to one of the magnesium-bound molecules. $(d)$ The $\alpha 1-\mathrm{L} \beta 5 \alpha 5$ interface made up by $\mathrm{Mg}-\mathrm{A}$ (right, blue) and Mg-B (left, orange). The monomers are superimposed on their Connolly solid surface and have been rotated to show the surfaces in contact. The $\mathrm{Mg}^{2+}$ ions coordinated in the active site are depicted as green spheres. The residues engaged in homodimeric interactions are shown by their number and their percentage of conservation (see \$2), ranging from $0 \%$ (pale yellow) to $100 \%$ (red). (e) $\mathrm{Mg}-\mathrm{A} / \mathrm{B}$ dimer superimposed with its Connolly solid surface coloured according to its electrostatic potential, from red $\left(-20 k_{\mathrm{B}} T / e\right)$ to blue $\left(+20 k_{\mathrm{B}} T / e\right)$. The view is the same as in Fig. 1(a), as indicated in the thumbnail. Note the continuous electronegative depression connecting both active sites, which contain $\mathrm{Mg}^{2+}$ ions shown as green spheres. $(f)$ Stereo plot showing the final $\left(2 m F_{\text {obs }}-d F_{\text {calc }}\right)$ electron density (contoured at $1 \sigma$ ) superimposed with the final refined model around the cationbinding site of $\mathrm{Mg}$-C. Intervening residues are displayed as sticks and labelled, as are participating solvent molecules (red spheres) and the magnesium cation (orange sphere). Hydrogen bonds and salt bridges are shown as violet lines and provided with a label indicating the distance (in $\AA$ ) between the interacting atoms. 
Glu96, which is at the end of helix $\alpha 4$ in a poorly defined region. All three molecules show two cis-peptide bonds between residues 44 and 45 and 105 and 106, respectively. Final refinement statistics are shown in Table 1. The coordinates for the refined PhoB model in complex with magnesium have been deposited with the Protein Data Bank at http// www.ebi.ac.uk/msd, with accession code 2yin. During the deposition procedure some atoms/residues where renamed/ renumbered by the PDB (see REMARKS section of the PDB entry).

\subsection{Miscellaneous}

Least-squares superimpositions were carried out with LSQMAN (Kleywegt \& Jones, 1994). In order to calculate the distances between similar atoms of different monomers, only the cores ( $\beta$-sheet strands) of the molecules were superimposed onto apo-PhoB RD molecule A (WT-A) and then compared. Dimer superimpositions were calculated using all $\mathrm{C}^{\alpha}$ atoms. The conservation values of residues within the OmpR/PhoB family of RD were computed as follows. Firstly, the 30 most similar sequences to PhoB were identified with PSI-BLAST (Altschul \& Koonin, 1998) and subjected to multiple alignment using ClustalW (both programs can be found at http://www.expasy.ch). The resulting sequence superposition was submitted to ESPript (Gouet, Courcelle et al., 1999), which converted the similarity values to pseudotemperature factors integrated into the PDB coordinates. Figures were produced with GRASP (Nicholls et al., 1991), SETOR (Evans, 1993b), MOLMOL (Koradi et al., 1996) and TURBO-FRODO (Carranza et al., 1999). The interface area between molecules was calculated using CNS. Identification of the residues involved in the protomer interactions was performed by visual inspection of the interfaces. The corresponding stereochemical analysis was performed by submitting the coordinates to the protein-protein interactions server http://www.biochem.ucl.ac.uk/bsm/PP/server/ index.html (Jones \& Thornton, 1996).

\section{Results}

\subsection{The interface of apo-PhoB RD (the ' $\alpha 1-\mathrm{L} / 35 a 5$ interface')} is not affected by $\mathrm{Mg}^{2+}$ binding

The addition of magnesium to PhoB RD prior to crystallization resulted in crystal growth under the same conditions as for the apo form, but in a new space group, $C 222_{1}$. In this new crystal form (PhoB RD bound to $\mathrm{Mg}^{2+}$; referred to in the following as $\mathrm{PhoB}^{\mathrm{RM}}$ ) there are three molecules per asymmetric unit, $\mathrm{Mg}-\mathrm{A}, \mathrm{Mg}-\mathrm{B}$ and $\mathrm{Mg}-\mathrm{C}$ (Fig. 1a), all of which contain an $\mathrm{Mg}^{2+}$ ion in the active site. Each monomer shows the PhoB RD doubly wound $(\alpha / \beta)_{5}$-fold consisting of a fivestranded twisted parallel $\beta$-sheet of topology $\beta 2 \beta 1 \beta 3 \beta 4 \beta 5$, flanked by two helices $(\alpha 1$ and $\alpha 5)$ on the concave side and three $(\alpha 2, \alpha 3$ and $\alpha 4)$ on the convex side (Fig. $1 b)$. Strands and helices alternate along the primary sequence and $\beta 1, \beta 3$ and $\beta 4$ form the protein core. The active site is located at the $\mathrm{C}$-terminal edge of the central $\beta$-sheet, in a wide cavity formed by loops connecting strands $\beta 1, \beta 3$ and $\beta 5$ with their subsequent helices $\alpha 1, \alpha 3$ and $\alpha 5$ (L $\beta 1 \alpha 1, \mathrm{~L} \beta 3 \alpha 3$ and $\mathrm{L} \beta 5 \alpha 5$, respectively). The last residue of $\beta 3$, Asp53, is the invariable phosphorylation site (Makino et al., 1989; Hiratsu et al., 1995). Glu9, Asp10 and Glu11 forms a conserved acidic triad in the active site (see \$3.4) that together with Asp53 confer a net negative charge on the cavity, which is extended by residues of the nearby segments $\mathrm{L} \beta 2 \alpha 2$ (Glu33 and Asp34), the N-terminus of helix $\alpha 2$ (Asp36) and helix $\alpha 4$ (Glu87, Glu88, Glu89 and Asp90). The fold in PhoB RD is conserved among other RDs belonging to the OmpR/PhoB subfamily, such as PhoP (PDB code 1mvo; Birck et al., 2003), DrrB (PDB code 1p2f; Robinson et al., 2003), DrrD (PDB code 1kgs; Buckler et al., 2002), $\mathrm{Rr}^{\mathrm{R}}{ }^{\mathrm{R}}$ (also termed MycA; PDB codes $1 \mathrm{nxt}$ and 1nxo; Bent et al., 2004), $\operatorname{ArcA}^{\mathrm{R}}$ (PDB codes 1xhe and 1xhf; Toro-Román, Mack et al., 2005), $\mathrm{KdpE}^{\mathrm{R}}$ (PDB codes 1zh2 and 1zh4; Toro-Román, Wu et al., 2005) and TorR ${ }^{\mathrm{R}}$, (PDB code 1zgz; Toro-Román, Wu et al., 2005), but also in more distant relatives RDs such as CheY (Stock et al., 1989), CheB (Djordjevic et al., 1998; Djordjevic \& Stock, 1998), NtrC (Volkman et al., 1995), Spo0F (Madhusudan et al., 1996), NarL (Baikalov et al., 1996), FixJ (Gouet, Fabry et al., 1999), DctD (Park et al., 2002), Spo0A (Lewis et al., 1999), ETR1 (MullerDieckmann et al., 1999) and DivK (Guillet et al., 2002).

Of the three molecules in $\mathrm{PhoB}^{\mathrm{RM}}$, only $\mathrm{Mg}$-B displays continuous electron density, whereas $\mathrm{Mg}-\mathrm{A}$ and $\mathrm{Mg}-\mathrm{C}$ show discontinuities at helix $\alpha 4$, making it difficult to trace the polypeptide chain. The root-mean-square deviation (r.m.s.d.) between Mg-A and $\mathrm{Mg}-\mathrm{B}$ is $0.35 \AA$ (for 110 common $\mathrm{C}^{\alpha}$ atoms deviating less than $3 \AA$ ), with maximal differences located at the ends of the loops flanking Mg-B helix $\alpha 4\left(\right.$ Gly86 C ${ }^{\alpha}, 2.6 \AA$; Leu95 $\mathrm{C}^{\alpha}, 1.6 \AA$ ). $\mathrm{Mg}$-B and Mg-C (r.m.s.d. of $0.27 \AA$ for 108 $\mathrm{C}^{\alpha}$ atoms) also deviate maximally in the same area (Ala84, $0.5 \AA$; Thr97, $1.8 \AA$ ). Mg-A and Mg-B establish the same dimer as described for monomers WT-A and WT-B in the apoprotein (PDB code 1b00; Solà et al., 1999; the r.m.s.d. between dimers is $0.61 \AA$ ), as they are related by an almost perfect non-crystallographic twofold axis to which both $\beta$-sheet C-termini converge (Fig. 1c), joining the two active sites in a large electronegative depression (Fig. 1e). Underneath and perpendicularly, the dimerization surfaces are selfcomplementary and glued by a hydrophobic core. The contact regions include helix $\alpha 1$, the loop $\mathrm{L} \beta 5 \alpha 5$ and the $\mathrm{N}$-terminus of helix $\alpha 5$ from both monomers (the $\alpha 1-\mathrm{L} \beta 5 \alpha 5$ interface). Between $\mathrm{Mg}$-A and $\mathrm{Mg}-\mathrm{B}$ the $\alpha 1-\mathrm{L} \beta 5 \alpha 5$ interface spreads over $578 \AA^{2}$ and the protomers are almost perfectly superimposable onto the WT-A/B dimer (r.m.s.d. of $0.61 \AA$; Fig. $1 c$ ). A stereochemical analysis of the interface area reveals that its size is just below the mean found for transient homodimer interaction surfaces $\left(740 \pm 139 \AA^{2}\right.$; Nooren \& Thornton, 2003). However, the rather small interaction area is compensated by a higher number of non-polar atoms $(74 \%$ in both $\mathrm{Mg}-\mathrm{A}$ and $\mathrm{Mg}-\mathrm{B}$ ) than the average for this kind of surface (65 $\pm 7 \%$; Nooren \& Thornton, 2003). The residues involved are Ile14, Met17, Phe20, Val21, Gln24 (all in $\alpha 1$ ), Pro106 (L $\alpha 1 \beta 1)$ and Pro109 (L $\beta 5 \alpha 5)$ from either protomer, plus Pro13 $(\alpha 1)$ from $\mathrm{Mg}$-A (Fig. 1d). The edge of the interface bordering the 
active site includes conserved positions within the $\mathrm{PhoB} /$ OmpR family (Ile14, 59\% and Pro106, 100\%), whereas the core of the interaction is non-conserved $(0 \%$ similarity; Fig. 1d). The same interaction appears again in the crystal via a crystallographic dyad between $\mathrm{Mg}-\mathrm{C}$ and $\mathrm{Mg}-\mathrm{C}^{\prime}$, a symmetryrelated molecule (Fig. 1c; deviation with respect to the WT dimer is $0.55 \AA$ ). In this case, the surface area is $544 \AA^{2}$ and the symmetric participants are the same, except that $G \ln 24$ is present and Phe107 is missing. In the WT-A/B dimer $\left(560 \AA^{2}\right.$ interacting surface), the same residues are observed, except that Phe107 and Pro13 are present and Gln24 is missing in both protomers. Note that the variable residues are limiting the interface, so their presence depends on small rearrangements between protomers in different dimers. Although this $\alpha 1-\mathrm{L} \beta 5 \alpha 5$ interface has not been reported in any other dimeric $\mathrm{RD}$, it has been found systematically in almost all crystals of $\mathrm{PhoB}$, namely the two apo-PhoB RD structures reported in different crystallization conditions (Solà et al., 1999; Bachhawat et al., 2005), $\mathrm{PhoB}^{\mathrm{RM}}$ (the present study) and two double-mutant structures (with similar stereochemical values of planarity and polarity, unpublished results). This interface is formed by both crystallographic and non-crystallographic dyads and it is present in crystals of different space groups, such as $P 2_{1} 2_{1} 2_{1}$ (Solà et al., 1999), $P 6_{1} 22$ (Bachhawat et al., 2005), $P 2_{1}$ and $C 222_{1}$ (unpublished results and this work). This specific dimer has been associated with the inactive state of PhoB by solution studies on apo-PhoB RD using analytical centrifugation, dynamic light-scattering and NMR measurements at different concentrations in absence of $\mathrm{Mg}^{2+}$ (Bachhawat et al., 2005). These studies indicated that these dimers are weak and are in equilibrium with monomers. All the present data suggest that $\mathrm{PhoB}$ has a strong tendency to preform the $\alpha 1-\mathrm{L} \beta 5 \alpha 5$ interaction during crystallization, probably induced by the high protein concentration, which displaces the equilibrium to the non-active dimeric form.

\subsection{The PhoB RD- $\mathbf{M g}^{2+}$ complex shows an incipient active interface (the 'Pre- $\alpha 4-\beta 5-\alpha 5$ interface')}

In the $\mathrm{PhoB}^{\mathrm{RM}}$ crystal form, $\mathrm{Mg}-\mathrm{B}$ and $\mathrm{Mg}-\mathrm{C}$ make a second type of interaction which involves helix $\alpha 4$ of $\mathrm{Mg}$-B and $\beta 5$ and helix $\alpha 5$ of both molecules (referred to in the following as the Pre- $\alpha 4-\beta 5-\alpha 5$ interface; see Fig. $1 a$ ). The prefix Pre- is included as the interacting surface can be envisaged as an intermediate state towards the final activated one (see below). The Pre- $\alpha 4-\beta 5-\alpha 5$ interaction surface buries only $382 \AA^{2}$ per monomer, contains more than $40 \%$ of polar residues and is not perfectly symmetric. Only three residues from each of $\mathrm{Mg}-\mathrm{B}$ and $\mathrm{Mg}-\mathrm{C}$ are directly involved in the interaction: Asp101 $(\beta 5), \operatorname{Arg} 115(\alpha 5)$ and $\operatorname{Arg} 122(\alpha 5)$ (Figs. $2 a$ and $2 b$ ). Mg-B makes additional interactions with the carbonyl $\mathrm{O}$ atom of Asp100 ( $\beta 5)$ and the side chains of Asp90 ( $\alpha 4)$, Tyr102 ( $\beta 5)$ and $\operatorname{Arg} 121(\alpha 5)$ and $\mathrm{Mg}$-C contributes the carbonyl groups of Ala99 (L $\beta 4 \alpha 5)$ and Tyr102 ( $\beta 5)$ and the side chains of Lys110 and Glu111 $(\alpha 5)$. The high flexibility of helix $\alpha 4$ in Mg-C further contributes to the asymmetry of this interface, as the residues therein do not take part in the contacts (Fig. 2b).
However, although all parameters point to a nonspecific crystal interaction, three features are of special interest. Firstly, the same segments belong to the dimerization interface of the fully activated RD of PhoB ( $\mathrm{PhoB}^{\mathrm{RAc}}$ ), the active site of which (Fig. 2f) contains an $\mathrm{Mg}^{2+}$ atom and a phosphoryl analogue, beryllium fluoride $\left(\mathrm{BeF}_{3}^{-}\right.$; Yan et al., 1999; Bachhawat et al., 2005). The $\mathrm{PhoB}^{\mathrm{RAc}}$ contacting area is symmetric and because it involves all three segments, helix $\alpha 4, \beta 5$ and helix $\alpha 5$ from both molecules ( $\alpha 4-\beta 5-\alpha 5$ interface), is much larger (890 $\AA^{2}$ per monomer). Secondly, the $\mathrm{Mg}-\mathrm{B}$ and $\mathrm{Mg}-\mathrm{C}$ interface contains residues that are highly conserved within the OmpR/PhoB family (Fig. 2a). Thirdly, RD structures of close relatives, such as the OmpR/PhoB family members $E$. coli $\mathrm{ArcA}^{\mathrm{R}}$ (Toro-Román, Mack et al., 2005; free or in complex with $\mathrm{Mg}^{2+}$ and $\mathrm{BeF}_{3}^{-}$) and the non-activated pneumococcal $\mathrm{MicA}^{\mathrm{R}}$ (Bent et al., 2004), have a very similar dimerization interface ( 850 and $995 \AA^{2}$, respectively) to $\mathrm{PhoB}^{\mathrm{RAc}}$. Further homologues with a similar interface include $\mathrm{KdpE}^{\mathrm{R}}$ and $\operatorname{Tor}^{\mathrm{R}}$ (Toro-Roman, Wu et al., 2005). It has been suggested that a similar oligomerization arrangement upon phosphorylation may occur for all $\mathrm{OmpR} / \mathrm{PhoB}$ family members (Bachhawat et al., 2005). A special feature of both the Pre- $\alpha 4-$ $\beta 5-\alpha 5$ and full $\alpha 4-\beta 5-\alpha 5$ interactions is that the two active sites within the dimer are separated by the interface segments and placed on opposite faces (Fig. 2c), unlike the Mg-A/B $\alpha 1$ $\mathrm{L} \beta 5 \alpha 5$ oligomer active sites, which lie within the same cavity (Fig. 1e).

The PhoB ${ }^{\mathrm{RAc}}$ structure shows three molecules, Be-A, Be-B and $\mathrm{Be}-\mathrm{C}$, in the asymmetric unit, which have $\mathrm{BeF}_{3}^{-}$and a $\mathrm{Mg}^{2+}$ ion at the active site (Bachhawat et al., 2005). Interestingly, Be-C makes contact with a symmetrically related molecule $\mathrm{A}^{\prime}\left(\mathrm{Be}-\mathrm{A}^{\prime}\right)$ through its $\alpha 1-\mathrm{L} \beta 5 \alpha 5$ surface; however, $\mathrm{Be}-\mathrm{A}^{\prime}$ is rotated $90^{\circ}$ with respect to $\mathrm{Mg}-\mathrm{A}$. Be-B and $\mathrm{Be}-\mathrm{C}$ interact through the $\alpha 4-\beta 5-\alpha 5$ interface, but several specific features differentiate it from the Pre- $\alpha 4-\beta 5-\alpha 5$ interaction seen in activated $\mathrm{PhoB}^{\mathrm{RM}}$. The two $\mathrm{PhoB}^{\mathrm{RM}} \mathrm{B} / \mathrm{C}$ and $\mathrm{PhoB}^{\mathrm{RAc}}$ $\mathrm{C} / \mathrm{B}$ dimers superpose with an r.m.s.d. of $3.31 \AA$. The deviations are generated by a relative rotation of $20^{\circ}$ of the respective subunits and because the corresponding interacting segments $(\alpha 4, \beta 5$ and $\alpha 5)$ are differently organized. The protomers $\mathrm{Mg}-\mathrm{B}$ and $\mathrm{Be}-\mathrm{C}$ (r.m.s.d. of $1.73 \AA$ for $120 \mathrm{C}^{\alpha}$ atoms) are equivalent in the dimer but deviate essentially at the $\mathrm{L} \beta 4 \alpha 4$ and helix $\alpha 4$ segments (if these segments are excluded, the r.m.s.d. reduces to $0.63 \AA$ for $105 \mathrm{C}^{\alpha}$ atoms). If we consider the $\mathrm{PhoB}^{\mathrm{RM}}$ structure as the $\mathrm{Mg}^{2+}$-bound precursor of $\mathrm{PhoB}^{\mathrm{RAc}}$, we can see that upon $\mathrm{BeF}_{3}^{-}$binding the peptide bond between Ala84 and Arg85 (at L $\beta 4 \alpha 4$ ) flips and the Arg85 side chain moves from the molecular surface to above the cleft between helices $\alpha 3$ and $\alpha 4$ and lies above the aromatic ring of Trp54. Moreover, helix $\alpha 4$ not only elongates (from Val92 in Mg-B to $\mathrm{Thr} 97$ in $\mathrm{Be}-\mathrm{C}$ ) but also rotates; therefore, the residues exposed in $\mathrm{PhoB}^{\mathrm{RM}}$ become oriented towards the protein core in $\mathrm{PhoB}^{\mathrm{RAc}}$ and vice versa. One example is Glu88, which interacts with the active site in $\mathrm{Mg}-\mathrm{B}$ or WT-A (Solà et al., 1999; Fig. 2d) but is driven to the solvent after the helical shift (Fig. 2f), or Asp90, which upon phosphorylation loses a salt bridge with $\mathrm{Mg}$-C Lys110 (helix $\alpha 5$ ) at 
the $\mathrm{PhoB}^{\mathrm{RM}}$ dimer interface (Fig. $2 b$ ). Val92 is the only hydrophobic residue that anchors helix $\alpha 4$ to the protein core (a)

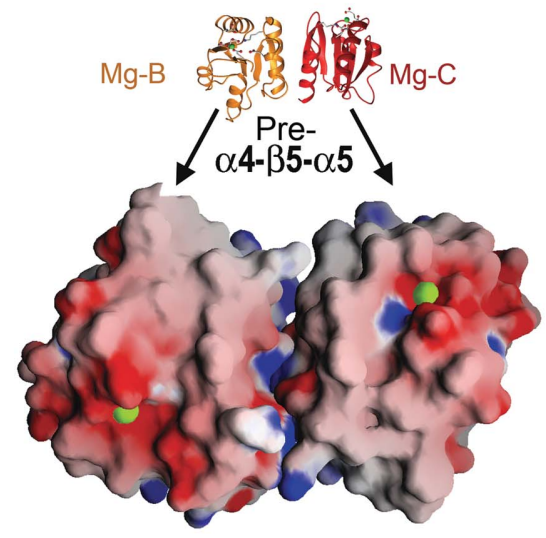

(c)

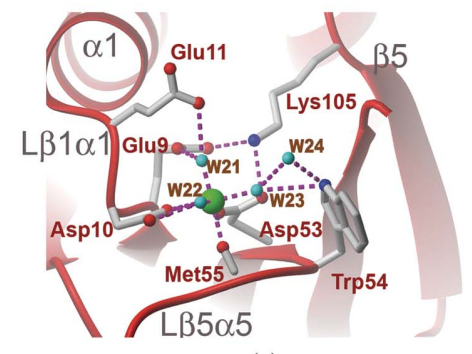

(e)

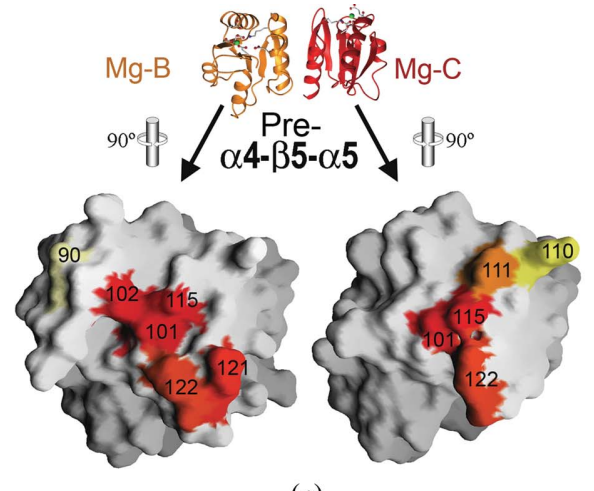

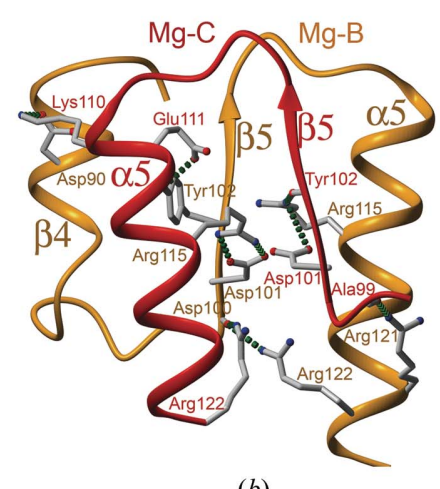

(b)

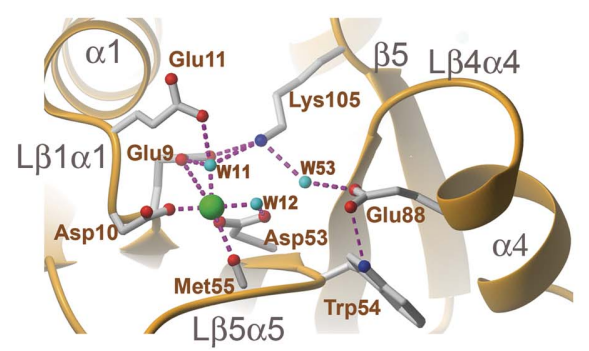

$(d)$

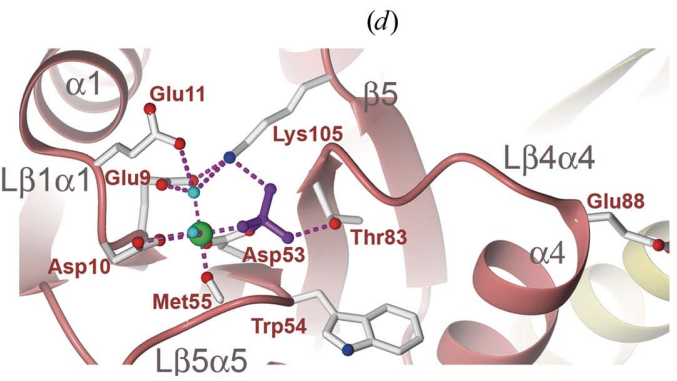

$(f)$
Figure 2

The Pre- $\alpha 4-\beta 5-\alpha 5$ interface. ( $a$ ) The $\alpha 4-\beta 5-\alpha 5$ interface is made up by Mg-B (left, orange) and Mg-C (right, red). Each constituent monomer (superimposed on its Connolly solid surface) has been rotated vertically $90^{\circ}$ from the position occupied in the small Richardson diagram to allow insight into the interacting surface. The residues of each molecule participating in direct contacts are shown and labelled. The colour coding, ranging from $0 \%$ (light yellow) to $100 \%$ (intense red), reflects the conservation of each position after sequence alignment. (b) Detail of the $\alpha 4-\beta 5-\alpha 5$ interface showing the side chains of the residues engaged in direct contacts from Mg-B (orange Richardson diagram) and $\mathrm{Mg}-\mathrm{C}$ (red). Hydrogen bonds and salt bridges are characterized by dashed lines. $(c)$ Representation of the Connolly surfaces of $\mathrm{Mg}-\mathrm{B}$ and $\mathrm{Mg}-\mathrm{C}$ protomers in $\mathrm{PhoB}^{\mathrm{RM}}$. The green spheres represent the two $\mathrm{Mg}^{2+}$ ions in the respective active sites, which are inside independent cavities orientated towards different faces. The two Mg-B and $\mathrm{Mg}-\mathrm{C}$ protomers contact by their $\alpha 4-$ $\beta 5-\alpha 5$ surfaces, although the interaction is not fulfilled (therefore, it is a Pre- $\alpha 4-\beta 5-\alpha 5$ interaction) as in activated PhoB (Fig. 2c; Bachhawat et al., 2005). (d) Close-up view of the active site of Mg-B. Only interactions involving side-chain atoms (except for Met55 O), the magnesium cation (green sphere) and solvent molecules are shown. Secondary-structure elements are indicated. Note the presence of Glu88 inside the cavity and the location of both the Trp54 side chain and the helix $\alpha 4$ segment. (e) Close-up view of $\mathrm{Mg}-\mathrm{C}$ active site with the same representation criteria as for $(d)$. Trp54 directly participates in the active-site network of interactions, while helix $\alpha 4$ is not organized. $(f)$ Close-up view of the Be-B active site activated with $\mathrm{BeF}^{-}$, represented in violet (Bachhawat $e t$ al., 2005). Helix $\alpha 4$ is shifted with respect to the $\mathrm{BeF}^{-}{ }^{-}$-free molecule $(d)$ and therefore Glu88 is orientated towards the surface of the domain. either in apo-PhoB RD or in $\mathrm{PhoB}^{\mathrm{RM}}$. Val92 has been transinterface by the helical rotation in PhoB ${ }^{\mathrm{RAc}}$, where it forms part of the interaction patch on the $\alpha 4-\beta 5-\alpha 5$ surface, which is symmetric, well defined and includes hydrophobic and hydrophilic contacts in $\mathrm{PhoB}^{\mathrm{RAc}}$ (Bachhawat et al., 2005). The RD structures of the PhoB orthologues Streptococcus pneumoniae $\mathrm{MicA}^{\mathrm{R}}$ (Bent et al., 2004) and E. coli $\mathrm{ArcA}^{\mathrm{RAc}}$ (Toro-Román, Mack et al., 2005), $\mathrm{KdpE}^{\mathrm{RAc}}$ and $\operatorname{TorR}^{\mathrm{R}}$ (ToroRomán, Wu et al., 2005), display the $\alpha 4$ $\beta 5-\alpha 5 \mathrm{PhoB}^{\mathrm{RAc}}$ interactions, with helix $\alpha 4$ also rotated. Positions in this $\alpha 4-\beta 5$ $\alpha 5$ conserved patch of interactions include invariable residues such as Asp101 (100\% conserved; Fig. 2a) and Arg115 (100\% conserved; Fig. 2a). In $\mathrm{PhoB}^{\mathrm{RAc}}$ these polar residues establish perfectly symmetric intermolecular salt bridges at the core of the interface. However, although these residues also meet at the Pre- $\alpha 4-\beta 5-\alpha 5$ interface in $\mathrm{PhoB}^{\mathrm{RM}}$, their interactions are not symmetric. Arg115 residues from either molecule make a stacking interaction through their guanidinium group (Fig. $2 b)$. Such an interaction is not possible in $\mathrm{PhoB}^{\mathrm{RAc}}$ owing to the relative rotation of the protomers with respect to $\mathrm{PhoB}^{\mathrm{RM}}$. Likewise, Arg122 from both $\mathrm{Mg}-\mathrm{B}$ and $\mathrm{Mg}-\mathrm{C}$ also interact and are further bound to the carbonyl $\mathrm{O}$ atom of Mg-B Asp101 (Fig. 2b). In PhoB ${ }^{\mathrm{RAc}}$, each of these arginines make a salt bridge with the Asp100 carboxylate from the opposite protomer. The $\mathrm{PhoB}^{\mathrm{RAc}}$ structure shows, like all the other activated RDs (e.g. Bent et al., 2004; Birck et al., 1999; Hastings et al., 2003; Lee, Cho, Pelton, Yan, Berry et al., 2001; Lee, Cho, Pelton, Yan, Henderson et al., 2001; Toro-Román, Mack et al., 2005; Toro-Román, Wu et al., 2005), Tyr102 (at $\beta 5)$ in a trans $(t)$ rotamer. The side chain is pointing towards $\mathrm{L} \beta 4 \alpha 4$, a movement allowed by the $t$ rotamer of Thr83 (end of $\beta 4$ ), which binds to one of the phosphoryl $\mathrm{O}$ atoms at the active site. These related orientations have been termed the YT coupling (Lee, Cho, Pelton, Yan, Berry et al., 2001) and imply respective $t / t$ conformations of both Thr83/Tyr102. In PhoB ${ }^{\mathrm{RM}}$, Tyr102 is located at the $\alpha 4-\beta 5-\alpha 5$ interface (Figs. $2 a$ and $2 b$ ). None of the PhoB ${ }^{\mathrm{RM}}$ 
protomers show the YT coupling, as the Thr83/Tyr 102 conformations are gauche $/$ gauche ${ }^{-}\left(g^{-} / g^{-}\right)$(in Mg-A), $g^{+} / g^{+}$ (Mg-B) and $g^{-} / g^{-}(\mathrm{Mg}-\mathrm{C})$. In $\mathrm{Mg}-\mathrm{C}$, helix $\alpha 4$ is disordered from Arg85 to Glu96, presumably abrogating the intramolecular interaction of Tyr102 with Arg93, thus inducing the $g^{-}$ conformation of Tyr102.

In summary, comparison of the $\mathrm{PhoB}^{\mathrm{RM}}$ and $\mathrm{PhoB}^{\mathrm{RAc}}$ structures shows that PhoB RD crystallized in complex with $\mathrm{Mg}^{2+}$ results in an increase of the flexibility of the $\alpha 4-\beta 5-\alpha 5$ surface that promotes a weak protein-protein contact in the crystal which resembles the final active interaction.

\subsection{Trp54 side-chain orientation depends on helix $a 4$ stability}

Trp54 is another interesting residue that fluorescence studies have identified as an indicator of PhoB activation (Zundel et al., 1998). It is placed at the beginning of $\mathrm{L} \beta 3 \alpha 3$, between two important positions: the phosphorylable Asp53 and the metal-coordinating Met55 (Fig. $2 d$; see $\$ 4$ ). In the WT-A and WT-B monomers, Trp54 is in a trans conformation, the side chain fitting snugly in a hydrophobic cavity between helices $\alpha 3$ and $\alpha 4$. Interestingly, in Mg-B the whole last turn of helix $\alpha 4$ unwinds from $\mathrm{Arg} 93$ on; Leu95 $\mathrm{C}^{\alpha}$, for example, is more than $5 \AA$ away from its position in WT and is exposed to the solvent. Consequently, the cavity that surrounds Trp54 in apo-PhoB disappears in $\mathrm{Mg}$ - $\mathrm{B}$. This residue rotates $30^{\circ}$ around its $\chi^{1}$ angle, bringing the indole ring close to the active site, where its $\mathrm{N}^{\varepsilon 1}$ hydrogen binds to Glu88 $\mathrm{O}^{\varepsilon 2}$ (Fig. $2 d$ ). The same correlation between rearrangements of helix $\alpha 4$ and Trp54 rotamers is found in both $\mathrm{Mg}-\mathrm{A}$ and $\mathrm{Mg}-\mathrm{C}$, where the instability of the entire helix $\alpha 4$ cancels a whole side of the Trp54 hydrophobic pillow. In Mg-A, Trp54 is poorly defined but residual density suggests that the side chain oscillates from $t$ to $g^{-}$conformations, alternating the position between the helices and the active-site edge. In $\mathrm{Mg}-\mathrm{C}$, the side chain of Trp54 rotates further than in Mg-A and penetrates into the active-site rim, where it is surrounded by Met55 ( $\beta 3)$ and the main chain of Thr83 and Ala84 ( $\beta 4$ end) (Fig. $2 e$ ). Indeed, its $\mathrm{N}^{\varepsilon 1}$ atom interacts with W23 from the magnesium coordination sphere (see $\$ 4$ and Figs. $1 f$ and $2 e$ ). The area that Trp54 side chain occupies in $\mathrm{Mg}-\mathrm{C}$ is the same as that filled by Glu88 in both WT protomers and Mg-B (Fig. 2d), which is empty in Mg-C owing to the disorder of helix $\alpha 4$ (Fig. 2e).

\subsection{Magnesium binding to the active site of PhoB RD reveals asymmetry inside the catalytic cavity}

The activated structure shows that the magnesium ion and the phosphate moiety (or its emulator $\mathrm{BeF}_{3}^{-}$) locate contiguously within the active site (see Fig. 2f; Birck et al., 1999; Hastings et al., 2003; Toro-Román, Mack et al., 2005; Bachhawat et al., 2005). We define two adjacent areas in the cavity: site $\mathrm{M}$ (for $\mathrm{Mg}^{2+}$ ) and site $\mathrm{P}$ (for phosphate). Site $\mathrm{M}$ is surrounded by $\mathrm{L} \beta 1 \alpha 1$, which includes residues involved in direct or indirect coordination to the $\mathrm{Mg}^{2+}$ atom, such as the highly conserved triad Glu9, Asp10 and Glu11. At the other end of the cavity, $\beta 4$ delimits site $\mathrm{P}$, where $\mathrm{Thr} 83 \mathrm{O}^{\gamma}$ and
Ala84 $\mathrm{N}$ are involved in phosphoryl oxygen (or $\mathrm{BeF}_{3}^{-}$ fluorine) binding (Fig. 2f). The $\mathrm{P}$ and $\mathrm{M}$ sites are bridged by the side chain of Asp53, which becomes phosphorylated on its $\mathrm{O}^{\delta 1}$ atom during activation and simultaneously binds the $\mathrm{Mg}^{2+}$ cation through its $\mathrm{O}^{\delta 2}$ atom. The following backbone of $\mathrm{L} \beta 3 \alpha 3$ is also partitioned, with the amide $\mathrm{N}$ atoms of positions 54 and 55 binding the phosphate moiety and the carbonyl $\mathrm{O}$ atom of residue 55 coordinating the cation. On the other side, Lys $105 \mathrm{~N}^{\zeta}$ (a nearly invariant residue) from $\mathrm{L} \beta 5 \alpha 5$ binds a phosphate $\mathrm{O}$ atom but contacts site $\mathrm{M}$ via the carboxylate of Glu9. Comparison of apo-RD structures of PhoB, ArcA, CheY, FixJ and DctD with their activated variants clearly shows that upon binding, the rigid cis-Pro-containing main chain adjacent to Lys105 transmits the movement to the neighbouring C-terminal end of $\beta 4$ and $\mathrm{L} \beta 4 \alpha 4$ (Santoro et al., 1995; Bellsolell et al., 1996).

In order to compare the $\mathrm{Mg}^{2+}$-bound active sites with each other and with the apo-PhoB RD molecules, only loops $\mathrm{L} \beta 1 \alpha 1$ and $\mathrm{L} \beta 5 \alpha 5$ were superimposed, as it is only around the $\mathrm{M}$ site that structures are rigid and comparable. Accordingly, the superposition of $\mathrm{Mg}-\mathrm{A}, \mathrm{Mg}-\mathrm{B}$ and $\mathrm{Mg}-\mathrm{C}$ molecules shows that the magnesium cations cluster at identical positions in all three active sites (differences are less than $0.2 \AA$ ). For the metal assignment at the density found at site $\mathrm{M}$, it was taken into account that $\mathrm{Mg}^{2+}, \mathrm{Na}^{+}$and solvent molecules are isoelectronic and therefore the distinction between them cannot be based on electron density or comparison of the temperature factors of surrounding atoms. Both sodium and magnesium typically display an octahedral coordination by six oxygen ligands, with a theoretical cation-oxygen distance of $2.46 \AA$ for $\mathrm{Na}^{+}$and $2.07 \AA$ for $\mathrm{Mg}^{2+}$ (Harding, 1999, 2002). Mg-C shows a complete octahedral coordination sphere for the cation (Fig. 1f), including Asp10 $\mathrm{O}^{\delta 1}\left(2.2 \AA\right.$ from $\left.\mathrm{Mg}^{2+}\right)$, Asp53 $\mathrm{O}^{\delta 2}(1.9 \AA)$ and Met55 O $(2.2 \AA)$. Solvent molecules W21 $(2.0 \AA)$, W22 $(2.1 \AA)$ and W23 $(2.2 \AA)$ complete the coordination. The same atoms coordinate the metal ion in $\mathrm{Mg}-\mathrm{A}$ and Mg-B except for the W22 equivalents, which are missing in these two molecules (Fig. 2d). The distances to the cation in $\mathrm{Mg}-\mathrm{A}$ (values for $\mathrm{Mg}-\mathrm{B}$ are given in parentheses) are Asp10 $\mathrm{O}^{\delta 1} 2.0 \AA(2.0 \AA), \operatorname{Asp} 53 \mathrm{O}^{\delta 2} 2.1 \AA(1.8 \AA)$, Met55 O $2.5 \AA(2.8 \AA)$, W1 $2.0 \AA$ (W11 $2.1 \AA$ ) and W2 $2.1 \AA$ (W12 $2.1 \AA$ ). Agreement between the three protomers is also observed for the side chains of Glu9, Asp10, Glu11 and Asp53 (Figs. $2 d$ and 2e). While Asp10 coordinates the magnesium ion, Glu9 and Gl11 interact with the metal through one of the apical coordinating water molecules (W2, W11 and W21 for $\mathrm{Mg}-\mathrm{A}, \mathrm{Mg}-\mathrm{B}$ and $\mathrm{Mg}-\mathrm{C}$, respectively; Figs. $2 d$ and $2 e$ ). In parallel, Glu9 establishes a highly conserved salt bridge with Lys105 N ${ }^{\zeta}$ (Solà et al., 1999; Welch et al., 1994; Park et al., 2002; Toro-Román, Mack et al., 2005; Bachhawat et al., 2005; ToroRoman, Wu et al., 2005), which shows good overlap (maximal deviation $0.4 \AA$ ) upon superposition of the $\mathrm{Mg}^{2+}$-bound structures shown here. This interaction is postulated (Solà et al. 1999) to fix the lysine $\mathrm{N}^{\zeta}$ in a position suitable for a further salt bridge with Asp53 $\mathrm{O}^{\delta 2}$, which is expected to be disrupted during the activation events. This leaves the Asp53 carboxylate oxygen free to act as the attacking nucleophile in the 
phosphotranspher reaction, as shown in $\mathrm{PhoB}^{\mathrm{RAc}}$ (Bachhawat et al., 2005). Furthermore, the Glu9-Lys105 salt bridge is complemented by a solvent bridge between Lys105 and Glu11 found in $\mathrm{Mg}-\mathrm{A}, \mathrm{Mg}-\mathrm{B}$ and WT-B. Another systematic feature is the mentioned apical position of the ion coordination sphere, occupied in the three $\mathrm{PhoB}^{\mathrm{RM}}$ protomers and also appearing in the metal-free WT-A molecule. In $\mathrm{Mg}$ - $\mathrm{B}$, the $\mathrm{Mg}^{2+}$-coordinating solvent molecules $\mathrm{W} 12$ and W53 extend the network of interactions to the rest of the active-site cavity (Fig. 2d). Overall, site M conserves the positions of the metalcoordinating protein atoms and the apical solvent molecules and some interactions appear very often, such as those established by Lys105 with Glu9, Glu11 and Asp53.

It is interesting that neither water molecules nor side chains are as prevalent in site $\mathrm{P}$ as in site $\mathrm{M}$. In $\mathrm{Mg}$-C, the Trp54 side chain penetrates the active site (see \$3.3) and interacts with the metal-coordinating solvent molecule W21 and with W24 (Figs. $1 f$ and $2 e$ ). In contrast, in Mg-B this side chain is located outside the cavity and the $\mathrm{P}$ site is filled by the carboxyl $\mathrm{O}$ atoms of Glu88, which can thus interact (Glu88 $\mathrm{O}^{\varepsilon 2}-$ Trp54 $\mathrm{N}^{\varepsilon 1}$, see Fig. $2 d$ ). Glu88 $\mathrm{O}^{\varepsilon 1}$ also interacts with Ala84 N (at $\beta 4$ ) and with another solvent molecule, W53, which links the glutamate to site M via Lys105 and the phosphorylable Asp53 (Fig. 2d). Glu88 is also present in the catalytic cavity in both WT-A and WT-B monomers, interacting with Ala84 N. Furthermore, in WT-A it forms a water bridge to Asp53 via the solvent molecule W53. Interestingly, this water molecule occupies the position of $\operatorname{Trp} 54 \mathrm{~N}^{\varepsilon 1}$ in Mg-C. In Mg-A, Glu88 is absent from the $\mathrm{P}$ site owing to the disorder of helix $\alpha 4$, but residual electron density suggests that the $\operatorname{Trp} 54$ indole ring partially penetrates the cavity, as mentioned in \$3.3. Summarizing, $\mathrm{PhoB}^{\mathrm{RM}}$ shows that the interactions appear to be regular at the $\mathrm{M}$ site, but there is a mutually exclusive presence of Glu88 and Trp54 at the P site. Both residues can make interactions inside the cavity. As explained above, the presence of Glu88 in the active site fixes helix $\alpha 4$, whilst the presence of Trp54 correlates with the destabilization of this helical segment. Taken together, our results show that upon $\mathrm{Mg}^{2+}$ binding, Glu88 may be substituted by $\operatorname{Trp} 54$ at the active site, resulting in the removal of an anchor of helix $\alpha 4$ with the protein core, thus promoting an unstructured state that may predispose this segment for an eventual shift at the final step of activation.

\subsection{Comparison of $\mathrm{Mg}^{2+}-\mathrm{PhoB}^{\mathrm{RM}}$ and $\mathrm{BeF}_{3}^{-}-\mathrm{PhoB}^{\mathrm{RAc}}$ active sites}

The superposition of the active sites of $\mathrm{Mg}-\mathrm{B}$ and the activated $\mathrm{PhoB}^{\mathrm{RAc}}$ molecule $\mathrm{Be}-\mathrm{C}$ shows that the $\mathrm{Mg}^{2+}$ ion and the atoms from the coordinating magnesium sphere fit very well (data not shown). Interestingly, the Mg-B metal-coordinating W12 coincides (at $0.4 \AA$ distance) with the position of one of the $\mathrm{BeF}_{3}^{-} \mathrm{F}$ atoms, $\mathrm{F} 1$, which also coordinates the $\mathrm{Mg}^{2+}$ (Figs. $2 d$ and $2 f$ ). In $\mathrm{PhoB}^{\mathrm{RAc}}$ the $\mathrm{F} 2$ and $\mathrm{F} 3$ atoms of $\mathrm{BeF}_{3}^{-}$are coordinated by the protein atoms $\mathrm{Thr} 83 \mathrm{O}^{\gamma}$ and Ala84 N, respectively (Bachhawat et al., 2005). Be, F2 and F3 form a plane and the central solvent molecule W53 of Mg-B is close to the F2-F3 edge of this plane. However, W53 does not bind to Ala84 $\mathrm{N}$ but rather to Glu88 $\mathrm{O}^{\varepsilon 1}$, which in turn is engaged in a hydrogen bond with Ala84 N (Fig. 2d). Therefore, the $\mathrm{Mg}-\mathrm{B}$ structure shows that binding of magnesium in the active site leads to an interaction between solvent molecules (W12 and W53) that emulates the molecular linkage between the fluorines in $\mathrm{BeF}_{3}^{-}$(Figs. $2 d$ and 2f). In Mg-A and Mg-C the presence of these interactions is prevented by the entrance of the Trp54 side chain, which is concomitant with the absence of Glu88 carboxylate owing to the disorder of helix $\alpha 4$ (Fig. 2e). In $\mathrm{PhoB}^{\mathrm{RAc}}$, Thr83 $\mathrm{O}^{\gamma}$ of $\mathrm{Be}-\mathrm{C}$, which coordinates the $\mathrm{F} 2$ atom (Fig. 2f), is closer (4.7 $\AA$ difference) to the active site than in Mg-B, owing to movement of $\beta 4$ and the rotation of the Thr83 side chain from $g^{-}$to $t$ conformation in the former molecule. The amide Ala $84 \mathrm{~N}$ of both $\mathrm{Mg}-\mathrm{B}$ and $\mathrm{Be}-\mathrm{C}$ are $1.8 \AA$ apart owing to the movement of $\beta 4$ in $\mathrm{PhoB}^{\mathrm{RAc}}$ towards the active site as it coordinates F3. Comparison of the $\mathrm{PhoB}^{\mathrm{RM}}$ and PhoB ${ }^{\mathrm{RAc}}$ structures suggests that once the $\mathrm{Mg}^{2+}$ ion is bound to the PhoB active site, the subsequently bound phosphate group (or $\mathrm{BeF}_{3}^{-}$molecule) substitutes both the metal-bound W12 and the W53 solvent molecules and drags the main chain of $\beta 4$ towards the active site, including both Thr83 and Ala84. Both events, the substitution of the solvent molecules and the $\beta 4$ movement, impede the interactions that Glu 88 or, in its absence, $\operatorname{Tr} 554$, establishes with the $\mathrm{Mg}^{2+}$-containing active site before phosphorylation (Figs. $2 d, 2 e$ and $2 f$ ).

\section{Discussion}

\subsection{Binding of the $\mathrm{Mg}^{2+}$ atom to PhoB RD promotes a transitory flexible conformation of helix $a 4$}

Active-site analysis of unbound PhoB RD and its complex with $\mathrm{Mg}^{2+}$ shows that there are two differentiated areas inside the cavity, the $\mathrm{M}$ site and the $\mathrm{P}$ site. The $\mathrm{M}$ site, framed by $\mathrm{L} \beta 1 \alpha 1$ and $\mathrm{L} \beta 3 \alpha 3$, harbours in all structures a network of interactions that persists upon addition of magnesium. In contrast, the $\mathrm{P}$ site shows a heterogeneous organization. In $\mathrm{Mg}-\mathrm{B}$, the solvent molecule W53 connects the network from the $\mathrm{M}$ site to the $\mathrm{P}$ site (Figs. $1 f$ and $2 d$ ). The interactions of solvent molecules W12 and W53 in the Mg-B active site are similar to the contacts established by the activating moiety $\left(\mathrm{BeF}_{3}^{-}\right)$in $\mathrm{PhoB}^{\mathrm{RAc}}$ (Figs. $2 d$ and $2 f$, respectively). Glu88 in site $\mathrm{P}$ participates in this network (Fig. $2 d$ ). In contrast, in the $\mathrm{P}$ sites of $\mathrm{Mg}-\mathrm{A}$ and $\mathrm{Mg}-\mathrm{C}$ neither solvent molecule W53 nor Glu88 is found (Fig. 2e). Instead, the Trp54 indole moiety is present and in $\mathrm{Mg}-\mathrm{C}$ it participates in the network of activesite interactions (Fig. 2e). In apo-PhoB ${ }^{\mathrm{R}}$, the Trp54 side chain is found between helices $\alpha 3$ and $\alpha 4$, which show different relative positions in WT-A and WT-B. However, despite these differences, the Trp54 rotamer is not altered. Rather, the versatile orientation of the indole moiety follows the conformational changes of the highly flexible helix $\alpha 4$. For example, in Mg-B the disorder of helix $\alpha 4$ at the C-terminus correlates with the position of the Trp54 side chain, which changes its van der Waals interaction partners from the lower to the upper part of the helical segment and makes an interaction with 
Glu88 (Fig. $2 d$ ). In Mg-A, and especially in $\mathrm{Mg}$-C, helix $\alpha 4$ is entirely disordered and Trp54 is immersed in the active-site rim, filling the space liberated by Glu88 (Fig. 2e). All these facts suggest a working model hypothesis. Upon $\mathrm{Mg}^{2+}$ complex formation, solvent molecules generate a new set of interactions in the active site occupying the position of the phosphate moiety in the activated form (Fig. $2 d$ ). Glu88 is bound to this network (Fig. $2 d$ ). However, these interactions are interrupted by the Trp54 side chain, which displaces Glu88 from the active site and concomitantly destabilizes helix $\alpha 4$ (Fig. 2e). Trp54 and Glu88 may alternate at the active site, with related intermittent disordered/ordered conformations of helix $\alpha 4$. Therefore, the presence of $\operatorname{Trp} 54$ in the active site contributes to an increase of the degrees of freedom of helix $\alpha 4$, which allows this segment to rotate. Once phosphorylation at Asp53 $\mathrm{O}^{\delta 1}$ occurs, Trp54 is displaced from the active site and Thr83 is attracted to the cavity, which allows Tyr102 to adopt the active $t$ conformation. $\mathrm{PhoB}^{\mathrm{RAc}}$ shows that $\operatorname{Trp} 54$ adopts a rotamer that fits the new conformation (elongated and shifted) of helix $\alpha 4$. Interestingly, CheY cocrystallized in the presence of $\mathrm{Mg}^{2+}$ (lacking the activating phosphate) shows a distortion of $\mathrm{L} \beta 4 \alpha 4$ and an unwinding of helix $\alpha 4$ (Bellsolell et al., 1994). Other cases where non-activated and activated RD structures can be compared include FixJ (Birck et al., 1999), DctD (Park et al., 2002) and NtrC (Hastings et al., 2003). Those show that residues at the position equivalent to $\operatorname{Trp} 54$ (Leu55 in FixJ, Ile56 in DctD and Ile55 in NtrC) undergo sidechain or even main-chain rotation to accommodate the YT coupling (involving equivalents of Thr83 and Tyr102), which also correlates with movements in helix $\alpha 4$. In $\mathrm{PhoB}^{\mathrm{RAc}}$, the side chain of Trp54 is within van der Waals distance of Thr83 and Tyr102 coupled residues, which are in $t$ conformations. According to all these data, inclusion of magnesium at the active site increases the interactions inside the cavity, but also induces an increase of flexibility of helix $\alpha 4$ that facilitate a conformational change of this segment, which is stabilized by phosphorylation. The movement of Trp54 as it enters the active site is a key feature in the process of PhoB activation. The full-length DrrB structure shows that destabilization of helix $\alpha 4$ could also lead to a release of the ED (Bachhawat $e t$ al., 2005).

\subsection{The inactive $\alpha 1-\mathrm{L} \beta 5 a 5$ interface is systematically present in all studied PhoB RD structures}

It was suggested that ablation of the C-terminal ED would eliminate the inactivating steric hindrance between domains and establish the functional RD active dimer, even in the absence of activating events (Fiedler \& Weiss, 1995). Except for the fully activated $\mathrm{PhoB}^{\mathrm{RAc}}$ (Bachhawat et al., 2005), all the ED-depleted PhoB RD dimers studied are joined by the $\alpha 1-\mathrm{L} \beta 5 \alpha 5$ interface, despite the crystals belonging to distinct space groups and the respective dyads of the dimers being either crystallographic or non-crystallographic. Indeed, preliminary structural studies on two constitutive double-point mutant RDs of PhoB RR further confirm this finding (unpublished results). Therefore, this interface appears in isolated PhoB RDs and in the absence of activating events and is reproducible in different crystal contexts. Biophysical studies indicated that it corresponds to a weak interaction (Bachhawat et al., 2005) promoted in the crystals perhaps because of the high protein concentration. The sequence analysis shows low conservation of the residues involved, suggesting that this interaction is specific to PhoB. However, this interface is distinct from that formed after PhoB RD activation by the phosphate analogue $\mathrm{BeF}_{3}^{-}$, as the $\mathrm{PhoB}^{\mathrm{RAc}}$ structure shows (Bachhawat et al., 2005). A recent model (Bachhawat et al., 2005) proposed that inactive $\mathrm{PhoB}$ is in an equilibrium between the $\alpha 1$-L $\beta 5 \alpha 5$-dimer and the monomeric forms and that phosphorylation of the monomer PhoB would lead to the active $\alpha 4-\beta 5-\alpha 5$ dimer. This model is consistent with Fiedler \& Weiss (1995) as well as with the dimers observed before and after phosphorylation (McCleary, 1996), which would correspond to two different oligomer forms. Our results show that the $\alpha 1-\mathrm{L} \beta 5 \alpha 5$ interface survives magnesium binding in this two-step activation. This suggests that the presence of magnesium does not affect the equilibrium between inactive $\alpha 1$-L $\beta 5 \alpha 5$-dimers and monomers, although helix $\alpha 4$ undergoes a transition between ordered and destabilized states triggered by Trp54. This might be the usual state of the PhoB receiver domain considering the intracellular levels of soluble $\mathrm{Mg}^{2+}$ in bacteria (4 $\mathrm{mM}$; Lusk et al., $1968)$. Our results also show the active conformation is initiated on the $\alpha 4-\beta 5-\alpha 5$ surface (Pre- $\alpha 4-\beta 5-\alpha 5$ ) and establishes a quasi-symmetric contact inside the crystal. Furthermore, inactive $\alpha 1-\mathrm{L} \beta 5 \alpha 5$ and Pre- $\alpha 4-\beta 5-\alpha 5$ interactions are compatible with each other. However, an in vivo $\alpha 1$-L $\beta 5 \alpha$ dimerdimer interaction through Pre- $\alpha 4-\beta 5-\alpha 5$, although conceivable, is unlikely because the corresponding stereochemical parameters suggest that the Pre- $\alpha 4-\beta 5-\alpha 5$ contact is very weak. Analysis of the activated $\mathrm{PhoB}^{\mathrm{RAc}}$ structure shows that the $\mathrm{Be}-\mathrm{C}$ protomer and a symmetrically related molecule Be$\mathrm{A}^{\prime}$ contact each other through their respective $\alpha 1$-L $\beta 5 \alpha 5$ surfaces, although these are rotated by $90^{\circ}$ relative to each other compared with $\mathrm{PhoB}^{\mathrm{RM}}$. This rotated $\alpha 1-\mathrm{L} \beta 5 \alpha 5$ interaction may be required for crystal formation. However, it could also be the result of phosphorylation on the $\alpha 1$ - $\mathrm{L} \beta 5 \alpha 5$ interaction. Moreover, in another related RD, Spo0F, this $\alpha 1$ $\mathrm{L} \beta 5 \alpha 5$ surface and the loops from the $\beta$-sheet $\mathrm{C}$-terminus are involved in the interaction with the cognate kinase phosphotransferase domain (Zapf et al., 2000). If PhoB had the same kind of interaction with PhoR, this would be an additional molecular strategy to prevent formation of the inactive $\alpha 1$ $\mathrm{L} \beta 5 \alpha 5$ dimer during phosphorylation.

We thank Jenny Colom for help during protein purification and Luis Serrano for support during the initial stages of the PhoB project. We also thank the DESY, ESRF and EMBL local contacts for providing assistance and support for measurements. MS is a beneficiary of the 'Ramon y Cajal' Programme from the Spanish Ministry for Science and Technology. Funding provided by research grants BIO2002-03964, BIO2003-132, GEN2003-20642 and BFU2005-06758/BMC 
from the same Ministry, as well as the help provided by the Generalitat de Catalunya (Centre de Referència en Biotecnologia and 2005SGR-00280), are further acknowledged.

\section{References}

Aizawa, S.-H., Harwood, C. \& Kadner, R. J. (2000). J. Bacteriol. 182, 1459-1471.

Altschul, S. F. \& Koonin, E. V. (1998). Trends Biochem. Sci. 23, 444-447.

Bachhawat, P., Swapna, G. V., Montelione, G. T. \& Stock, A. M. (2005). Structure Fold. Des. 13, 1353-1363.

Baikalov, I., Schröder, I., Kaczor-Grzeskowiak, M., Gunsalus, R. P. \& Dickerson, R. E. (1996). Biochemistry, 35, 11053-11061.

Barrett, J. F. \& Hoch, J. A. (1998). Antimicrob. Agents Chemother. 42 , 1529-1536.

Bellsolell, L., Cronet, P., Majolero, M., Serrano, L. \& Coll, M. (1996). J. Mol. Biol. 257, 116-128.

Bellsolell, L., Prieto, J., Serrano, L. \& Coll, M. (1994). J. Mol. Biol. 238, 489-495.

Bent, C. J., Isaacs, N. W., Mitchell, T. J. \& Riboldi-Tunnicliffe, A. (2004). J. Bacteriol. 186, 2872-2879.

Birck, C., Chen, Y., Hulett, F. M. \& Samama, J. P. (2003). J. Bacteriol. 185, 254-261.

Birck, C., Mourey, L., Gouet, P., Fabry, B., Schumacher, J., Rousseau, P., Kahn, D. \& Samama, J. P. (1999). Structure Fold. Des. 7, 15051515.

Blanco, A. G., Solà, M., Gomis-Rüth, F. X. \& Coll, M. (2002). Structure Fold. Des. 10, 701-713.

Brünger, A. T., Adams, P. D., Clore, G. M., DeLano, W. L., Gros, P., Grosse-Kunstleve, R. W., Jiang, J.-S., Kuszewski, J., Nilges, M., Pannu, N. S., Read, R. J., Rice, L. M., Simonson, T. \& Warren, G. L. (1998). Acta Cryst. D54, 905-921.

Buckler, D. R., Zhou, Y. \& Stock, A. M. (2002). Structure Fold. Des. 10, 153-164.

Carranza, C., Inisan, A.-G., Mouthuy-Knoops, E., Cambillau, C. \& Roussel, A. (1999). AFMB Activity Report 1996-1999, pp. 89-90. Marseille: CNRS-UPR 9039.

Djordjevic, S., Goudreau, P. N., Xu, Q., Stock, A. M. \& West, A. H. (1998). Proc. Natl Acad. Sci. USA, 95, 1381-1386.

Djordjevic, S. \& Stock, A. M. (1998). J. Struct. Biol. 124, 189-200.

Ellison, D. W. \& McCleary, W. R. (2000). J. Bacteriol. 182, 6592-6597.

Evans, P. (1993a). Proceedings of the CCP4 Study Weekend. Data Collection and Processing, edited by L. Sawyer, N. Isaacs \& S. Bailey, pp. 114-122. Warrington: Daresbury Laboratory.

Evans, S. V. (1993b). J. Mol. Graph. 11, 134-138.

Falke, J. J. \& Hazelbauer, G. L. (2001). Trends Biochem. Sci. 26, 257-265.

Fiedler, U. \& Weiss, V. (1995). EMBO J. 14, 3696-3705.

Forsberg, J., Rosenquist, M., Fraysse, L. \& Allen, J. F. (2001). Biochem. Soc. Trans. 29, 403-407.

Gouet, P., Courcelle, E., Stuart, D. I. \& Metoz, F. (1999). Bioinformatics, 15, 305-308.

Gouet, P., Fabry, B., Guillet, V., Birck, C., Mourey, L., Kahn, D. \& Samama, J. P. (1999). Structure Fold. Des. 7, 1517-1526.

Grefen, C. \& Harter, K. (2004). Planta, 219, 733-742.

Guillet, V., Ohta, N., Cabantous, S., Newton, A. \& Samama, J. P. (2002). J. Biol. Chem. 277, 42003-42010.

Harding, M. M. (1999). Acta Cryst. D55, 1432-1443.

Harding, M. M. (2002). Acta Cryst. D58, 872-874.

Hastings, C. A., Lee, S. Y., Cho, H. S., Yan, D., Kustu, S. \& Wemmer, D. E. (2003). Biochemistry, 42, 9081-9090.

Hiratsu, K., Nakata, A., Shinagawa, H. \& Makino, K. (1995). Gene, 161, 7-10.

Hoch, J. A. (2000). Curr. Opin. Microbiol. 3, 165-170.

Huber, R. (1965). Acta Cryst. 19, 353-356.
Jones, S. \& Thornton, J. M. (1996). Proc. Natl Acad. Sci. USA, 93, $13-20$.

Kleywegt, G. J. \& Jones, T. A. (1994). Jnt CCP4/ESF-EACBM Newsl. Protein Crystallogr. 31, 9-14.

Koradi, R., Billeter, M. \& Wüthrich, K. (1996). J. Mol. Graph. 14, $51-55$.

Laskowski, R. A., MacArthur, M. W., Moss, D. S. \& Thornton, J. M. (1993). J. Appl. Cryst. 26, 283-291.

Lee, S.-Y., Cho, H. S., Pelton, J. G., Yan, D., Berry, E. A. \& Wemmer, D. E. (2001). J. Biol. Chem. 276, 16425-16431.

Lee, S.-Y., Cho, H. S., Pelton, J. G., Yan, D., Henderson, R. K., King, D. S., Huang, L., Kustu, S., Berry, E. \& Wemmer D. E. (2001). Nature Struct. Biol. 8, 52-56.

Leslie, A. G. W. (1991). Crystallographic Computing V, edited by D. Moras, A. D. Podjarny \& J. C. Thierry, pp. 27-38. Oxford University Press.

Lewis, R. J., Brannigan, J. A., Muchova, K., Barak, I. \& Wilkinson, A. J. (1999). J. Mol. Biol. 294, 9-15.

Lukat, G. S., Stock, A. M. \& Stock, J. B. (1990). Biochemistry, 29, 5436-5442.

Lusk, J. E., Williams, R. J. P. \& Kennedy, E. P. (1968). J. Biol. Chem. 243, 2618-2624.

McCleary, W. R. (1996). Mol. Microbiol. 20, 1155-1163.

McCleary, W. R. \& Stock, J. B. (1994). J. Biol. Chem. 269, 3156731572.

Madhusudan, Zapf, J., Whiteley, J. M., Hoch, J. A., Xuong, N.-H. \& Varughese, K. I. (1996). Structure Fold. Des. 4, 679-690.

Makino, K., Shinagawa, H., Amemura, M., Yamasa, M. \& Nakata, A. (1989). J. Mol. Biol. 210, 551-559.

Matthews, B. W. (1968). J. Mol. Biol. 33, 491-497.

Muller-Dieckmann, H. J., Grantz, A. A. \& Kim, S.-H. (1999). Structure Fold. Des. 7, 1547-1556.

Murshudov, G. N., Vagin, A. A. \& Dodson, E. J. (1997). Acta Cryst. D53, 240-255.

Navaza, J. (1994). Acta Cryst. A50, 157-163.

Nicholls, A., Sharp, K. \& Honig, B. (1991). Proteins, 11, 281296.

Nooren, I. M. \& Thornton, J. M. (2003). J. Mol. Biol. 325, 9911018.

Pao, G. M. \& Saier, M. H. Jr (1997). J. Mol. Evol. 44, 605-613.

Park, S., Meyer, M., Jones, A. D., Yennawar, H. P., Yennawar, N. H. \& Nixon, B. T. (2002). FASEB J. 16, 1964-1966.

Peränen, J., Rikkonen, M., Hyvonen, M. \& Kääriäinen, L. (1996). Anal. Biochem. 236, 371-373.

Robinson, V. L., Wu, T. \& Stock, A. M. (2003). J. Bacteriol. 185, 41864194.

Santoro, J., Bruix, M., Pascual, J., López, E., Serrano, L. \& Rico, M. (1995). J. Mol. Biol. 247, 717-725.

Santos, J. L. \& Shiozaki, K. (2001). Sci. STKE, 2001, RE1.

Solà, M., Gomis-Rüth, F. X., Guasch, A., Serrano, L. \& Coll, M. (1998). Acta Cryst. D54, 1460-1463.

Solà, M., Gomis-Rüth, F. X., Serrano, L., Gonzalez, A. \& Coll, M. (1999). J. Mol. Biol. 285, 675-687.

Stephenson, K. \& Hoch, J. (2002). Curr. Opin. Pharmacol. 2, 507512.

Stock, A. M., Mottonen, J. M., Stock, J. B. \& Schutt, C. E. (1989). Nature (London), 337, 745-749.

Stock, A. M., Robinson, V. L. \& Goudreau, P. N. (2000). Annu. Rev. Biochem. 69, 183-215.

Toro-Román, A., Mack, T. R. \& Stock, A. M. (2005). J. Mol. Biol. 349, $11-26$.

Toro-Román, A., Wu, T. \& Stock, A. M. (2005). Protein Sci. 14, 3077 3088.

Volkman, B. F., Nohaile, M. J., Amy, N. K., Kustu, S. \& Wemmer, D. E. (1995). Biochemistry, 34, 1413-1424.

Wang, W., Zhang, W., Chen, H., Chiao, J., Zhao, G. \& Jiang, W. (2002). Arch. Microbiol. 178, 376-386.

Wanner, B. L. (1993). J. Cell. Biochem. 51, 47-54. 
Wanner, B. L. (1996). Escherichia coli and Salmonella typhimurium: Cellular and Molecular Biology., edited by F. C. Neidhardt, R. I. Curtiss, J. L. Ingraham, E. C. Lin, K. B. J. Low, B. Magasanik, W. Reznikoff, M. Riley, M. Schaechter \& H. E. Umbarger, pp. 13571381. Washington, DC: American Society for Microbiology.

Welch, M., Oosawa, K., Aizawa, S.-I. \& Eisenbach, M. (1994). Biochemistry, 33, 10470-10476.

Wick, L. M. \& Egli, T. (2004). Adv. Biochem. Eng. Biotechnol. 89, $1-45$.
Wolanin, P. M., Thomason, P. A. \& Stock, J. B. (2002). Genome Biol. 3 , 1-8.

Yan, D., Cho, H. S., Hastings, C. A., Igo, M. M., Lee, S. Y., Pelton, J. G., Stewart, V., Wemmer, D. E. \& Kustu, S. (1999). Proc. Natl Acad. Sci. USA, 96, 14789-14794.

Zapf, J., Sen, U., Madhusudan, Hoch, J. A. \& Varughese, K. I. (2000). Structure Fold. Des. 8, 851-862.

Zundel, C. J., Capener, D. C. \& MacCleary, W. R. (1998). FEBS Lett. 441, 242-246. 